\title{
Factors associated with antenatal mental disorder in West Africa: A cross-sectional survey
}

Bola Ola ${ }^{1}$, Jim $\mathrm{Crabb}^{2 *}$, Adetokunbo Tayo ${ }^{3}$, Selena H Gleadow Ware ${ }^{4}$, Arup Dhar ${ }^{4}$ and Rajeev Krishnadas ${ }^{5}$

\begin{abstract}
Background: Maternal mental illness is likely to have a profound impact in less developed parts of the world. A mother experiencing mental illness in a low income setting is at risk of providing sub-optimal care for her offspring which can have grave consequences in an environment where poverty, overcrowding, poor sanitation, malnutrition, tropical diseases and a lack of appropriate medical services may be pronounced. Given the profound consequences of antenatal and postnatal mental illness on maternal mental health, foetal wellbeing and childhood growth and development the factors associated with mental illness in a Sub-Saharan setting merit clarification and investigation.
\end{abstract}

Methods: A prospective survey design was conducted in Lagos. Self reporting questionnaire 20 items - SRQ20 assessed the presence of mental illness. The WHO Multi-country Study on Women's Health and Domestic Violence Questions assessed women's exposure to violence. Numerous variables potentially associated with mental illness including maternal socio-economic factors, maternal characteristics, obstetric variables and the characteristics of previous children were recorded. Direct logistic regression was performed to assess the impact of a number of variables on the likelihood of presence of mental disorder in the population.

Results: 189 women were surveyed. $7 \%$ met the criteria for experiencing a common mental disorder according to their score on the SRQ-20. Of variables examined only the number of female children and the presence of inter personal violence predicted being a case of mental illness $(O R=3.400 ; 95 \% \mathrm{Cl}=1.374-8.414$ and $\mathrm{OR}=5.676 ; 95 \%$ $\mathrm{Cl}=1.251-25.757$ respectively).

Conclusions: Rates of mental disorder found in our study were lower than those previously observed internationally and in Africa, perhaps reflecting stigma about disclosing symptoms. The predictive nature of violence on mental disorder is in keeping with international evidence. Our study demonstrated that exposure to inter personal violence within the last 12 months and increasing numbers of female children predict the presence of mental illness in a sample of pregnant Nigerian women. Training and education for primary health care and obstetric health workers should highlight these areas.

\section{Background}

There is increasing evidence that anxiety and depression are more prevalent in late pregnancy compared to the postpartum period and an increasing body of evidence highlights the role of antenatal stress on maternal mental health and childhood growth and development [1]. Pre-natal stress has been identified as referring to a range of events from exposure to traumatic events, selfreports of daily hassles and negative life events during pregnancy [2]. A number of independent studies have

\footnotetext{
* Correspondence: jcrabb1@nhs.net

${ }^{2}$ Forth Valley Royal Hospital, Stirling Road, Larbert, UK

Full list of author information is available at the end of the article
}

found associations between antenatal stress and adverse neurobehavioral outcomes including impaired social, emotional and cognitive functioning during childhood [3]. Antenatal stress has also been associated with preterm delivery and low birth weight, poor attendance at antenatal clinics as well as elevated risk of cardiovascular disease later in life [4-6].

Maternal stress and mental illness is likely to have a profound impact in less developed parts of the world. A mother experiencing mental illness in a low income setting is at risk of providing sub-optimal care for her offspring which can have grave consequences in an environment where poverty, overcrowding, poor

\section{() Biomed Central}


sanitation, malnutrition, tropical diseases and a lack of appropriate medical services may be pronounced $[7,8]$. Adewuya et al in their report on the impact of postnatal depression on infants' growth in Nigeria, found statistically significant poorer growth rates in infants of depressed mothers, compared to non-depressed mothers at 3 and 6 months postpartum [9]. Depressed mothers were found to be more likely to stop breastfeeding earlier and their infants were more likely to have episodes of diarrhoea and other infectious illnesses.

Given the profound consequences of antenatal and postnatal mental illness on maternal mental health, foetal wellbeing and childhood growth and development in Sub Saharan Africa it is important as a first step to ascertain the scale of the problem, particularly as epidemiological studies have been scarce in the region. Once this has been established it will also be vital for policy makers and clinicians to be able to identify those at risk of developing mental disorder in pregnancy so that preventative measures can be implemented.

\section{Methods}

\section{Sampling}

Our study had a prospective survey design and was conducted in Lagos, the largest city in Nigeria. Lagos has an estimated population of 15 million and has two teaching hospitals with psychiatric facilities and one psychiatric hospital. Consecutive pregnant women attending the antenatal clinic at the maternity clinic of the Lagos State University Teaching Hospital, Ikeja, for routine appointments over an eight week period were interviewed. Non pregnant women, women with other health problems attending clinic and family members were excluded. We estimated sample size using a method proposed by Daniel [10]. International systematic reviews have shown the prevalence of antenatal depression to be 7.4-12\% [11]. Assuming that the prevalence rate of mental disorder in Nigeria would be $10 \%$, using a $95 \%$ confidence interval and a precision of $5 \%$ we calculated a sample size of 144 .

\section{Procedures}

Participants gave written informed consent which was based on the procedure used by the WHO Multi-country Study on Women's Health and Domestic Violence [12]. Consent forms were approved by local health workers and service users for acceptability. Ethical approval was granted by the Ethics and Research Committee of Lagos State University Teaching Hospital, Ikeja. All subjects were able to read, write and converse fluently in English and completed the following measures.

\section{Measures}

In order to measure the presence of mental illness our study employed the self reporting questionnaire 20 items (SRQ20). This consists of twenty yes/no questions with a reference period of the previous thirty days. It has acceptable levels of reliability and validity in developing countries and is recommended by the World Health Organisation (WHO) as a screening tool [13]. It has previously been used to measure maternal illness in a four country study which included Ethiopia where a cut off score of $7 / 8$ was used to separate probable noncases/cases of common mental disorder [14].

The WHO Multi-country Study on Women's Health and Domestic Violence Questions were used to assess women's exposure to violence [12]. Rather than being an exhaustive list a limited number of questions about specific acts that occur in violent partnerships are covered. This approach has been found to encourage greater disclosure of violence. Psychometric analysis has been performed on the terms used in the questionnaire which were found to be valid and reliable measures for each type of violence. The WHO ethical and safety guidelines for domestic violence research were adhered to throughout our study [15]. Practices developed in the WHO Multi-country Study on Women's Health and Domestic Violence to ensure confidentiality, minimize distress and provide support to women experiencing inter personal violence were also implemented [12].

Our literature review highlighted numerous variables potentially associated with mental illness including maternal socio-economic factors, maternal characteristics, obstetric variables and the characteristics of previous children $[12,14]$. Details regarding these variables were recorded in our sample population. Raters were trained to use manualised versions of the above rating scales and questionnaire. Two raters assessed the same thirty cases and the inter-rater reliability was found to be acceptable with a kappa's coefficient of 0.89 .

\section{Statistical methods}

Statistical analysis was done using SPSS version 17 [16]. Binary logistic regression was performed to assess the impact of a number of variables on the likelihood of presence of common mental disorder caseness in the population. The dependent variable was caseness based on a cut off score of $7 / 8$ on the SRQ 20 scores. We tested the effects of 9 independent variables, based on previous studies. They were age, household income, receiving help from partner, number of previous female children, history of physical violence in last 12 months, perceived difficulty meeting daily needs, primi-parity, planned current pregnancy and a history of substance use.

\section{Results}

200 women attended the clinic over the 8 week period. 189 were surveyed, 11 refused to participate giving a 
response rate: $94.5 \%$. Demographic and obstetric details are shown in Table 1.

13 women interviewed (7\%) met the criteria for experiencing a common mental disorder according to their score on the SRQ-20. With regards to physical violence, $12.2 \%$ (23) of women had ever been exposed to violence. 9.5\% (18) had experienced physical violence within the last 12 months whilst 5.3\% (10) were currently suffering this form of abuse. Our analysis focused on interpersonal violence exposure within the last 12 months as this period would correspond with all of the current pregnancy.

There were no differences between cases and noncases on age $(\mathrm{MW}=1035.0 ; \mathrm{p}=0.56)$ and gestational age of current pregnancy $(\mathrm{MW}=1000.5 ; \mathrm{p}=0.45)$. All patients were either in their second or third trimesters (range $=16-36$ months). Results of the binary logistic regression predicting caseness is shown in table 2 . The model containing all 9 predictors was statistically significant $\left(\chi^{2}=16.9 ; \mathrm{df}=9 ; \mathrm{p}=0.05\right)$, indicating that the model was able to distinguish between cases and noncases. The model as a whole explained around $22 \%$ of the variance in caseness. As shown in table 1, the strongest predictor was a history of physical violence in the last 12 months, recording an odds ratio of 5.67. This

\section{Table 1 Demographic and obstetric factors}

\begin{tabular}{|c|c|c|}
\hline \multicolumn{2}{|l|}{ Age [mean; s.d.] } & $30.28(4.4)$ \\
\hline \multicolumn{2}{|l|}{ Primipara [n;\%] } & $52(27.5 \%)$ \\
\hline \multicolumn{2}{|l|}{$\begin{array}{l}\text { Number of previous female kids [mean; } s \text {. } \\
\text { d.] }\end{array}$} & $0.45(0.66)$ \\
\hline \multicolumn{2}{|l|}{ Gestational age [mean; s.d.] } & $\begin{array}{l}26.59 \\
(4.65)\end{array}$ \\
\hline \multicolumn{2}{|l|}{ History of IPV in the past 12 months [n;\%] } & $18(9.5 \%)$ \\
\hline \multicolumn{2}{|l|}{ Difficulty meeting needs [n;\%] } & $41(21.7 \%)$ \\
\hline \multicolumn{2}{|l|}{ Unplanned pregnancy [n;\%] } & $29(15.3 \%)$ \\
\hline \multicolumn{2}{|l|}{ History of substance use $[n ; \%]$} & $21(11.1 \%)$ \\
\hline \multirow[t]{5}{*}{ Patient's income $[n ; \%]$} & $\begin{array}{l}\text { Less than } \\
20000\end{array}$ & $49(25.9 \%)$ \\
\hline & 20000-49999 & $97(51.3 \%)$ \\
\hline & 50000-79999 & $40(21.2 \%)$ \\
\hline & 80000 - 99999 & $2(1.1 \%)$ \\
\hline & 100000 -above & $1(0.5 \%)$ \\
\hline \multirow[t]{5}{*}{ Partner's income [n;\%] } & $\begin{array}{l}\text { Less than } \\
20000\end{array}$ & $3(1.6 \%)$ \\
\hline & 20000-49999 & $50(26.5 \%)$ \\
\hline & $50000-79999$ & $94(49.7 \%)$ \\
\hline & $80000-99999$ & $31(16.4 \%)$ \\
\hline & 100000 -above & $11(5.8 \%)$ \\
\hline \multicolumn{2}{|l|}{ No perceived help from partner [n;\%] } & $37(19.6 \%)$ \\
\hline \multicolumn{2}{|l|}{ History of Higher Education [n;\%] } & $\begin{array}{l}142 \\
(75.1 \%)\end{array}$ \\
\hline
\end{tabular}

indicated that those who experienced physical abuse during the last 12 months were over 5 times more likely to be a case than those who were not physically abused, controlling for all other factors in the model. The odds ratio of 3.4 for the number of previous female children indicated that for every additional previous female child in the family, a woman was 3 times more likely to have a common mental disorder. None of the other variables predicted caseness. After adding gestational age into the model, it failed to be statistically significant $\left(\chi^{2}=16.94\right.$; $\mathrm{df}=10 ; \mathrm{p}=0.076$; Nagelkerke $\left.\mathrm{R}^{2}=0.218\right)$.

\section{Discussion}

Systematic reviews of studies in Europe and North America have shown the prevalence of antenatal depression at the first, second, and third trimesters to be 7.4, 12.8 , and $12 \%$, respectively with major depression affecting up to $12.7 \%$ of women $[11,17]$. A recent comprehensive review of the literature regarding pre and post natal mental health in Africa reported rates of antenatal depression and anxiety of $11.3-13.1 \%$ and $14.8 \%$ respectively across the continent [18]. Our study found lower rates of mental disorder of $7 \%$, a figure comparable with other studies examining maternal mental health in Nigeria, which identified depression rates of $8.3-10.3 \%$ $[19,20]$. The disparity between rates of mental illness in Nigeria and Africa as a whole may in part be explained by the particularly high rates of stigma regarding mental illness in West Africa, which might prevent a woman disclosing symptoms of mental illness. This interpretation is supported by our findings that none of the women in our study reported a previous personal or familial history of mental illness. Typical West African cultural explanations for mental disorder include criminality, spirit possession \& punishment accompanied with fears that individuals with mental illness are mentally retarded and/or dangerous [21]. In the context of pregnancy these misconceptions may be particularly stigmatising as women may fear that disclosing a past or familial history of mental illness could suggest that their child may be already damaged by association with mental illness. With regards to anxiety symptoms our results were lower than another study by Adewuya et al which found rates of anxiety of $39 \%$ in pregnant Nigerian women compared to $16.3 \%$ in the non pregnant population [19]. This difference may reflect the differences in methodology, particularly the rating scale used. In the work by Adewuya et al anxiety was measured according to DSM-IV criteria whilst the SRQ-20 employed in our study measures a combination of mood and anxiety symptoms (see limitations).

Recent systematic reviews of the literature from the United States, Canada, Europe, Australia and New Zealand have identified the following risk factors for 
Table 2 Logistic regression predicting caseness on SRQ20

\begin{tabular}{lccccc}
\hline & B & S.E. & Wald $\boldsymbol{\chi}^{\mathbf{2}}$ & Sig. & Odds Ratio (95\% C.I) \\
\hline Age & -.045 & .078 & .328 & .56 & $0.956(0.821-1.114)$ \\
\hline Household income & -.074 & .171 & .187 & .66 & $0.929(0.665-1.298)$ \\
Receiving no help from partner & 1.084 & .805 & 1.815 & .17 & $2.956(0.611-14.307)$ \\
Number of previous female children & 1.224 & .462 & 7.007 & .008 & $3.400(1.374-8.414)$ \\
\hline History of physical violence in last 12 months & 1.736 & .772 & 5.062 & .024 & $5.676(1.251-25.757)$ \\
\hline Perceived difficulty meeting daily needs & .471 & .691 & .465 & .49 & $1.602(0.413-6.206)$ \\
Primi-para & 1.162 & .865 & 1.805 & .18 & $3.196(0.587-17.406)$ \\
\hline Planned current pregnancy & .498 & .806 & .381 & .54 & $1.645(0.339-7.986)$ \\
\hline History of substance use & -.074 & .966 & .006 & .94 & $0.929(0.140-6.173)$ \\
Constant & -2.942 & 2.376 & 1.534 & .216 & .053 \\
\hline
\end{tabular}

Dependent variable: Caseness (1); Model $\chi^{2}=16.9 ; \mathrm{df}=9 ; \mathrm{p}=0.05$; Nagelkerke

$\mathrm{R}^{2}=0.22$. All categorical risk factors are coded as " 0 " for absence of risk factor and " 1 " for presence of risk factor.

depressive symptoms in pregnancy; maternal anxiety, life stress, history of depression, lack of social support, unintended pregnancy, Medicaid insurance, domestic violence, lower income, lower education [22]. The following factors were found to have no association with antenatal mental illness; smoking, alcohol use, illicit drug use, parity, maternal race/ethnicity, maternal age and obstetric history (including spontaneous abortions, elective abortions, and foetal deaths in-utero) [22]. Adewuya's studies in West Africa identified correlates of antenatal anxiety including younger age, primiparity and the presence of medical problems as well as risk factors for antenatal depression including hospital admissions during pregnancy; female sex of the baby; preterm delivery; instrumental delivery; caesarean section, previous still birth, perceived lack of social support and being single/separated or polygamous. Esimai's later study which measured fewer variables found that a low level of partner intimacy and a lack of financial support were associated with antenatal depression and anxiety [20]. Aside from these studies there is inconclusive evidence from studies across Africa that socioeconomic variables are implicated in antenatal mental health [18]. Our study only found an association between mental disorder and one of these variables, the number of previous female children. The sex of the child has been hypothesized as a potentially important risk factor in certain less developed parts of the world where there may be social and cultural pressures on women to give birth to sons [23]. This is particularly the case in Nigeria where women are held culpable for the sex of the baby and lack of a male heir is often cited as a reason for relationship break down [24].

To date we are not aware of any other work which has examined the relationship between antenatal mental illness and exposure to interpersonal violence in West Africa. Our finding of a positive relationship between violence and symptoms of mental disorder is in keeping with previous evidence. Bivariate studies have shown a small association between domestic violence and depressive symptoms whilst multivariate studies show a small to medium association [22]. In 1 study of 128 women in North America, a history of abuse within the past year was associated with almost 2.5 times the odds of a positive screen for depression [25]. Similarly work from North America and Europe has established a strong association between suicidality and IPV exposure $[26,27]$. Though our results had a wide confidence interval this most likely reflects the small prevalence of caseness

\section{Limitations}

The use of an arbitrary cut off point on the SRQ-20 to define a 'case' of mental disorder may have introduced measurement bias and could explain the sharp difference between cases of anxiety found in Adewuya's study and cases of mental illness found in our own $[19,28]$. Inadequacies in the ability of the SRQ 20 to detect mental disorder in a Nigerian population may explain our low rate of caseness. The scale has however been validated in a number of Sub Saharan African countries. In the Uganda a cut of score of 6 has been used to denote psychological distress [29]. A more recent validation study in Rwanda, published after our data had been recorded suggested the scale had different cut off points for men and women, with ten being identified in females [30]. In the absence of a validation study from West Africa our use of 8 as a cut off point seems reasonable based on the evidence available.

A number of challenges exist in implementing antenatal care in Africa. Late booking is particularly common in Nigeria, particularly in multiparous women, and has been found to be associated with educational level of partners, previous miscarriage and medical problems in the index pregnancy [31]. It has been suggested that most Nigerian woman wish to give birth on their own 
because of the pride associated with unassisted delivery and the loss of esteem associated with operative interventions [32]. It is possible then that selection bias was present in our study as our sample consisted of woman motivated to attend medical clinics in an urban area. All women in our study could also read, write and speak English therefore our results may not be generalisable to rural populations where this is not the case. Our sample does perhaps represent the evolving face of West Africa that is experiencing increasing urbanisation and socioeconomic development. This may have influenced our findings in several ways. It is possible that an urban, educated population might have more progressive views about female offspring, mental illness and the role of obstetric care, compared to their rural counterparts. Pregnant women in rural facilities outside of the mainstream health system may be therefore less likely to report levels of mental disorder due to greater levels of stigma. An alternative explanation is that women in urban areas are more vulnerable to psycho-social stresses similar to those that women in higher income countries experience relating to social change, including urbanisation and the breakdown of family networks and traditional support systems. If this were the case we would expect to find differences in levels of mental disorder in urban compared to rural samples. Such data is however lacking from the existing evidence base. Firm conclusions about the potential bias caused by our sample are therefore impossible at this stage. Our study contributes to the emerging view that there are characteristics of maternal mental illness unique to Sub Saharan Africa. Further research is however required to compare rates of common mental disorder and risk factors in pregnant women from different geographical areas and socioeconomic backgrounds within the region.

\section{Conclusions}

Our study demonstrated that exposure to physical violence within the last 12 months and increasing numbers of female children predict the presence of mental illness in a sample of pregnant Nigerian women. We suggest that questions regarding mental illness and inter personal violence should be included in standard obstetric screening in Sub Saharan Africa. More detailed psychiatric screening including thoughts of suicide should be considered for any woman reporting exposure to inter personal violence. Women with multiple female offspring should also be screened for mental illness in Sub Saharan Africa. Training and education for primary health care and obstetric health workers should highlight these areas. Although no causative links can be inferred from the results of our study, broader community and population approaches to addressing inter personal violence and cultural expectations of infant gender may be required, to reduce the psychosocial and cultural stressors pregnant women face, that may increase vulnerability to mental illness during the perinatal period. It is likely that successful interventions to improve maternal mental health in Sub Saharan Africa need to involve political, social, and educational approaches, as well as ensuring appropriate screening by healthcare professionals.

\section{Abbreviations}

SRQ: Self reporting questionnaire 20 items; WHO: World Health Organisation; O.R: Odds ratio;

\section{Author details}

'Department of Behavioural Medicine, LASUCOM Ikeja, Lagos, Nigeria. ${ }^{2}$ Forth Valley Royal Hospital, Stirling Road, Larbert, UK. ${ }^{3}$ Department of Obstetrics and Gynaecology LASUCOM Ikeja, Lagos, Nigeria. ${ }^{4}$ Riverside Resource Centre Community Mental Health Team, 8 Sandy Rd, Glasgow, UK. ${ }^{5}$ Sackler Institute of Psychobiological Research, Section of Psychological Medicine, Southern General Hospital, Glasgow, UK.

\section{Authors' contributions}

$\mathrm{BO}$ and $\mathrm{AT}$ were involved in the design and implementation of the study including data collection. JC devised the study design and wrote the paper. SG \& AD conducted the literature review. RK performed the statistical analysis and helped preparing the manuscript. All authors contributed to and approved the final draft of the text.

\section{Competing interests}

The authors declare that they have no competing interests.

Received: 2 July 2011 Accepted: 4 November 2011

Published: 4 November 2011

\section{References}

1. Heron J, O'Connor TG, Evans J, Golding J, Glover V: The course of anxiety and depression through pregnancy and the postpartum in a community sample. Journal of affective disorders 2004, 80(1):65-73.

2. Talge NM, Neal C, Glover V: Antenatal maternal stress and long-term effects on child neurodevelopment: how and why? Journal of child psychology and psychiatry, and allied disciplines 2007, 48(3-4):245-261.

3. Wadhwa PD: Psychoneuroendocrine processes in human pregnancy influence fetal development and health. Psychoneuroendocrinology 2005, 30(8):724-743.

4. Hedegaard M, Henriksen TB, Sabroe S, Secher NJ: Psychological distress in pregnancy and preterm delivery. BMJ (Clinical research ed 1993, 307(6898):234-239.

5. Pagel MD, Smilkstein G, Regen H, Montano D: Psychosocial influences on new born outcomes: a controlled prospective study. Social science \& medicine 1982, 30(5):597-604, 1990

6. Barker DJ, Eriksson JG, Forsen T, Osmond C: Fetal origins of adult disease: strength of effects and biological basis. International journal of epidemiology 2002, 31(6):1235-1239.

7. Patel V, DeSouza N, Rodrigues M: Postnatal depression and infant growth and development in low income countries: a cohort study from Goa, India. Archives of disease in childhood 2003, 88(1):34-37.

8. Rahman A, Lovel H, Bunn J, lqbal Z, Harrington R: Mothers' mental health and infant growth: a case-control study from Rawalpindi, Pakistan. Child: care, health and development 2004, 30(1):21-27.

9. Adewuya AO, Ola BO, Aloba OO, Mapayi BM, Okeniyi JA: Impact of postnatal depression on infants' growth in Nigeria. Journal of affective disorders 2008, 108(1-2):191-193.

10. Daniel WW: Biostatistics: a foundation for analysis in the health sciences. New York; Chichester: Wiley; 71999.

11. Bennett HA, Einarson A, Taddio A, Koren G, Einarson TR: Prevalence of depression during pregnancy: systematic review. Obstetrics and gynecology 2004, 103(4):698-709. 
12. Garcia-Moreno C, Heise L, Jansen HA, Ellsberg M, Watts C: Public health. Violence against women. In Science. Volume 310. New York, NY; 2005:(5752):1282-1283.

13. Beusenberg M, Orley J: A user's guide to the self reporting questionnaire (SRQ). In. Edited by.Edited by: Health DoM. Geneva: WHO; 1994:.

14. Harpham T, Huttly S, De Silva MJ, Abramsky T: Maternal mental health and child nutritional status in four developing countries. Journal of epidemiology and community health 2005, 59(12):1060-1064.

15. WHO: Putting women first: ethical and safety recommendations for research on domestic violence against women. Geneva: World Health Organization; 1999.

16. SPSSInc: SPSS Base 17.0 for Windows User's Guide. Chicago IL: SPSS Inc; 2009.

17. Gaynes BN, Gavin N, Meltzer-Brody S, Lohr KN, Swinson T, Gartlehner G, Brody S, Miller WC: Perinatal depression: prevalence, screening accuracy, and screening outcomes. Evidence report/technology assessment (Summary) 2005, 119: 1-8.

18. Sawyer A, Ayers S, Smith H: Pre- and postnatal psychological wellbeing in Africa: a systematic review. Journal of affective disorders 2010, 123(13):17-29.

19. Adewuya AO, Ola BA, Aloba OO, Mapayi BM: Anxiety disorders among Nigerian women in late pregnancy: a controlled study. Archives of women's mental health 2006, 9(6):325-328.

20. Esimai $O A$, Fatoye FO, Quiah AG, Vidal OE, Momoh RM: Antepartum anxiety and depressive symptoms: A study of Nigerian women during the three trimesters of pregnancy. J Obstet Gynaecol 2008, 28(2):202-203.

21. Gureje O, Lasebikan VO, Ephraim-Oluwanuga O, Olley BO, Kola L: Community study of knowledge of and attitude to mental illness in Nigeria. Br J Psychiatry 2005, 186:436-441.

22. Lancaster CA, Gold K, Flynn HA, Yoo H, Marcus SM, Davis MM: Risk factors for depressive symptoms during pregnancy: a systematic review. American journal of obstetrics and gynecology 2010, 202(1):5-14.

23. Patel V, Rahman A, Jacob KS, Hughes M: Effect of maternal mental health on infant growth in low income countries: new evidence from South Asia. BMJ (Clinical research ed 2004, 328(7443):820-823.

24. Adewuya A, Aloba O: Reproductive mental health risk in Nigeria: myths, facts and challenges. International Psychiatry 2009, 6(4):84.

25. Jesse DE, Walcott-McQuigg J, Mariella A, Swanson MS: Risks and protective factors associated with symptoms of depression in low-income African American and Caucasian women during pregnancy. Journal of midwifery \& women's health 2005, 50(5):405-410.

26. Houry D, Kemball R, Rhodes KV, Kaslow NJ: Intimate partner violence and mental health symptoms in African American female ED patients. The American journal of emergency medicine 2006, 24(4):444-450.

27. Kaslow $N$, Thompson M, Meadows $L$, Chance $S$, Puett $R$, Hollins $L$, Jessee $S$, Kellermann A: Risk factors for suicide attempts among African American women. Depression and anxiety 2000, 12(1):13-20.

28. Adewuya AO, Ola BA, Aloba OO, Dada AO, Fasoto OO: Prevalence and correlates of depression in late pregnancy among Nigerian women. Depression and anxiety 2007, 24(1):15-21.

29. Abbo C, Ekblad S, Waako P, Okello E, Muhwezi W, Musisi S: Psychological distress and associated factors among the attendees of traditional healing practices in Jinja and Iganga districts, Eastern Uganda: a crosssectional study. Int J Ment Health Syst 2008, 2(1):16.

30. Scholte WF, Verduin F, van Lammeren A, Rutayisire T, Kamperman AM: Psychometric properties and longitudinal validation of the self-reporting questionnaire (SRQ-20) in a Rwandan community setting: a validation study. BMC Med Res Methodol 11:116.

31. Adeyemi AB, Makinde ON, Ajenifuja KO, Soyinka AS, Ayinde AK, Ola BA, Ofili M: Determinants of antenatal booking time in a South-Western Nigeria setting. West African journal of medicine 2007, 26(4):293-297.

32. Loto OM, Adewuya AO, Ajenifuja OK, Orji EO, Owolabi AT, Ogunniyi SO: The effect of caesarean section on self-esteem amongst primiparous women in South-Western Nigeria: a case-control study. J Matern Fetal Neonatal Med 2009, 22(9):765-769.

\section{Pre-publication history}

The pre-publication history for this paper can be accessed here:

http://www.biomedcentral.com/1471-2393/11/90/prepub doi:10.1186/1471-2393-11-90

Cite this article as: Ola et al:: Factors associated with antenatal mental disorder in West Africa: A cross-sectional survey. BMC Pregnancy and Childbirth 2011 11:90

\section{Submit your next manuscript to BioMed Central and take full advantage of:}

- Convenient online submission

- Thorough peer review

- No space constraints or color figure charges

- Immediate publication on acceptance

- Inclusion in PubMed, CAS, Scopus and Google Scholar

- Research which is freely available for redistribution

Submit your manuscript at www.biomedcentral.com/submit
Ciomed Central 